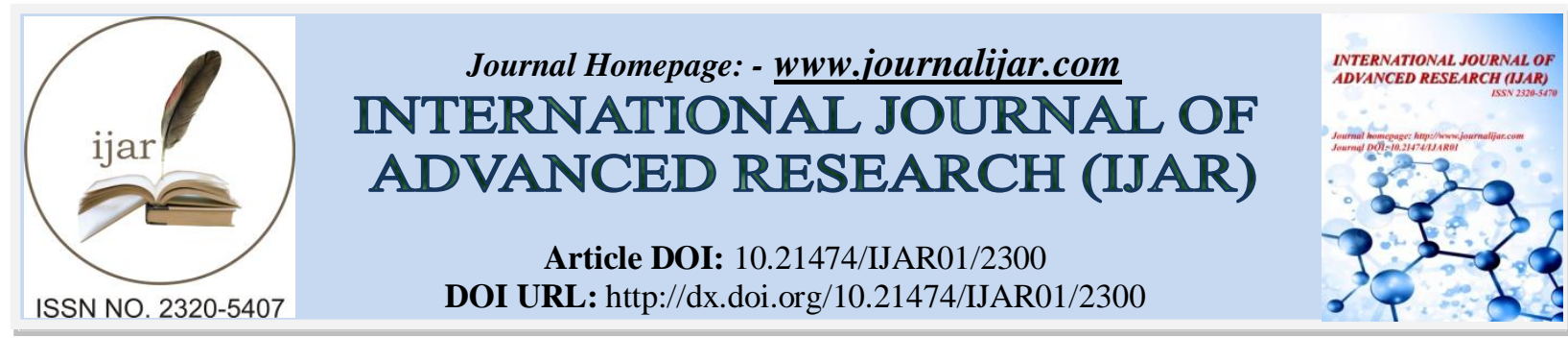

RESEARCH ARTICLE

\title{
PEDIATRIC INTENSIVE CARE-UNIT ACQUIRED WEAKNESS (PICUAW).
}

\author{
Tarek A. Attia ${ }^{1}$, Samir M. Zamzam ${ }^{1}$, Doaa M. Sharaf ${ }^{2}$ and Tarek A. Belasy ${ }^{1}$. \\ 1. Pediatric Medicine Department, Faculty of Medicine, Zagazig University. \\ 2. Rheumatology and Rehabilitation Department, Faculty of Medicine, Zagazig University.
}

\section{Manuscript Info}

\section{Manuscript History}

Received: 29 September 2016

Final Accepted: 30 October 2016

Published: November 2016

Key words:-

Critical illness polyneuropathy, critical illness myopathy and pediatric ICUAW

\begin{abstract}
Critical illness polyneuropathy (CIP) and critical illness myopathy (CIM) are major complications that occur in severely ill patients especially in intensive care unit. The aim of this work was to highlight on critical illness polyneuropathy and myopathy in pediatric intensive care unit and its relation to difficult weaning from mechanical ventilation. Patients and Method: The study included 50 children. The patients were selected as simple random sample. All children were subjected to full history taking, laboratory tests, EMG and NVC. Results: ICUAW incidence in our studied sample was high $62 \%$ and had significant relation to the duration of ventilation and some risk factors like age, multiple causes, and some laboratory parameters. Conclusions: It becomes clear from the research that the incidence of PICUAW was high especially when pathological factors associated with the disease. We recommended neurophysiologic testing for early diagnosis of weakness, control of causal factors such as the level of blood sugar, and minimizing the length of the period of mechanical ventilation.
\end{abstract}

Copy Right, IJAR, 2016,. All rights reserved.

\section{Introduction:-}

Intensive care unit-acquired weakness (ICUAW) has been recognized as an important and persistent complication in survivors of critical illness [1,2]. Critical illness polyneuropathy (CIP) and critical illness myopathy (CIM) are overlapping syndromes of widespread muscle weakness and neurological dysfunction that can develop in critically ill patients receiving intensive care [3]. Acquired neuromuscular weakness due to critical illness polyneuropathy and myopathy (CIPNM) frequently develops in patients hospitalized in the intensive care unit for more than one week. CIPNM may present with muscle weakness and failure to wean from mechanical ventilation, but is discovered more often and earlier by electrophysiological examination. Neuromuscular weakness is often encountered in patients in the intensive care unit (ICU) [4].

Patients can be admitted to the ICU because of increasing muscle weakness and threating respiratory failure due to underlying neuromuscular disorder, mainly Guillian Barre Syndrome (GBS) and myathania gravis. Neuromuscular weakness can also be acquired: it frequently develops in the setting of critical illness in patients admitted to the ICU because of multi-trauma, severe infections, or (multiple) organ dysfunction. Neuromuscular weakness in critically ill patients may be caused by a polyneuropthy, myopathy or neuromuscular blockade [5]. All of the reported patients were admitted to the ICU and during a period of critical illness with sepsis and multi-organ failure requiring artificial respiration, the patients developed a severe sensory-motor polyneuropathy. The polyneuropathy was axonal and could therefore be differentiated from demylinating form of GBS. Acute quadriplegic myopathy with selective myosin loss 
and acute necrotizing myopathy are considered to be a separate entity, as a part of critical illness myopathy [6]. The basic pathophysiology of CIPNM is complex and involves metabolic, inflammatory and bioenergetic alterations [7]. The network of proposed pathophysiological mechanisms involved in the development of critical illness polyneuropathy and myopathy is shown in the figure below [8]

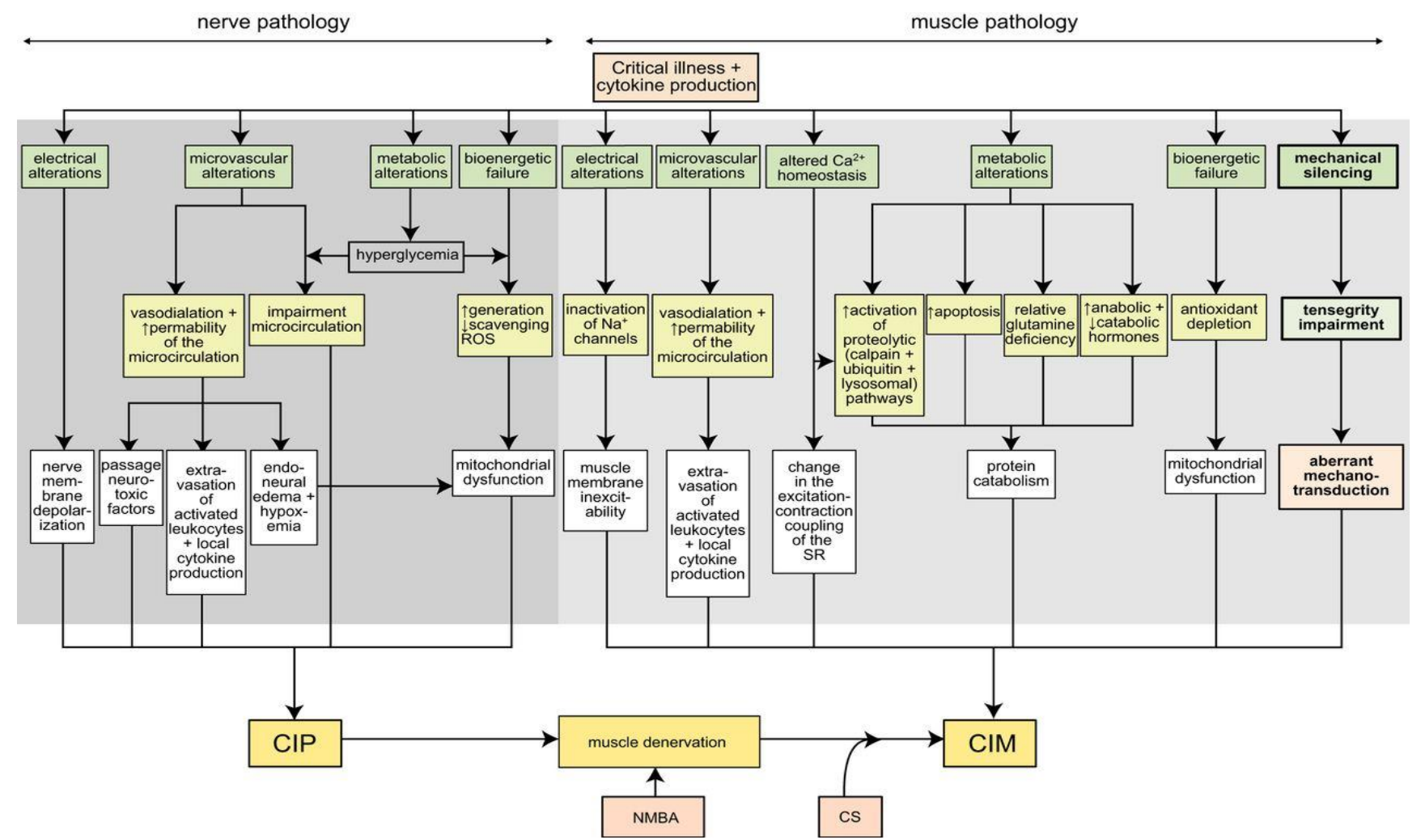

Figure 1:- Summary of pathophysiological mechanisms in ICU-related weakness $(\mathrm{CS}=$ corticosteroid , NMBA= neuromuscular blocking agent)[6]

CIP and CIM are well recognized in adults, in whom they commonly cause generalized weakness and muscle wasting, with failure to wean from mechanical ventilation [9]. The aim of this work was to highlight on critical illness polyneuropathy and myopathy in pediatric intensive care unit and its relation to difficult weaning from mechanical ventilation.

\section{The patients and Methods:-}

This study was conducted in the pediatric intensive care unit (PICU) of Pediatric Department and Rheumatology and Rehabilitation Department, Zagazig University Hospitals, with approval of institutional ethics committee. A written informed consent was obtained from the parents of each patient or their guardians. The study included 50 children. The patients were selected as simple random sample, and were subjected to full history taking, laboratory tests, EMG and NCV. Patients admitted to the PICU due to neurological or muscular etiology was excluded from our study. The neurological examination was performed twice a week during the stay in the intensive care unit and once a week in the general ward until recovery. The examination assessed motor deficit, muscle wasting, sensory loss and tendon reflexes. Medical Research Council (MRC) sum score evaluates muscle force on a scale from 0 to 5 in three muscle groups of both upper and lower limbs (upper arm abductors, elbow flexors, wrist extensors, hip flexors, knee extensors and foot dorsal flexors), rendering a maximum score of 60 [4].

In the non-cooperative only tendon reflexes and motor sum score on pain stimuli were scored consisting of flexion in the elbow and flexion the hip, with a maximum sum score of 10.

For the clinical assessment of CIPNM, only the motor sum score and tendon reflexes counted at least 3 days after the use of neuromuscular blocking agents was stopped 


\section{Clinical and electrophysiological criteria of CIPNM [10]:}

Patients used no neuromuscular blocking agents for at least 3 days for both clinical and electrophysiological criteria. For diagnosis of CIAPNM clinical and electrophysiological criteria should met [10]:

Clinical: present for at least two consecutive visits.

Co- operative patients:

- Motor Sum Score $<26$

- Decreased or absent tendon reflexes.

Non co- operative patients:

- Motor Sum Score $<8$

Electrophysiological

- Decreased or absent tendon reflexes.

Presence of axonal polyneuropathy as in I or II:-

I- distal CMAP ulnar nerve absent or below $<4.2 \mathrm{mV}$ and entrapment at the elbow and demyelination were excluded And Distal CMAP peroneal nerve absent or below $<2.6 \mathrm{mV}$ and entrapment at the fibular headand demyelination were excluded

II- Criteria for ulnar or peroneal nerves as mentioned above And Spontaneous activity of muscle fibers in rest (fibrillations or positive waves) in at least two of the examined muscles Ratio of the area of proximal CMAP versus the distal CMAP $>0.89$ in the nerve with decreased CMAP amplitude

\section{Electrophysiological studies:-}

Motor and sensory conduction studies were carried out from four motor (ulnar and peroneal bilaterally) and four sensory nerves (ulnar and sural nerves bilaterally) using conventional techniques. Abnormalities of CMAP or SNAP amplitudes were considered significant if found in at least two nerves.

Needle EMG from four muscles (deltoid, first dorsal interosseus, tibial anterior and abductor hallucis muscles) was performed with assessment of spontaneous activity and, if possible, recruitment and interference patterns. The presence of spontaneous activity was considered significant if found from at least two muscles

All electrophysiological tests were performed at the bedside with a Nicolet Viking IV apparatus. Electrophysiological studies and normal reference values were evaluated according to the description of Preston and Shapiro [11]

\section{Statistical analysis:-}

Data were analyzed by the Statistical Package for the Social Sciences (SPSS version 20.0) (Statistical Package for the Social Sciences) software for analysis. Student T test, Mann Whitney U (MW) test and $\mathrm{X}^{2}$ (chi-squared) significance test were used. Significance value $(\mathrm{P})$ was set at $<0.05$ for significant results and $<0.001$ for highly significant results.

\section{Results:-}

Our study included 50 pediatric patients ( 29 girls and 21 boys) with a mean of age $55.3 \pm 39.8$ months. Their descriptive and laboratory parameters data were shown in (table 1). The weakness / myopathy percentage was $62 \%$, neuropathy $54 \%$ and neuropathy and myopathy together $54 \%$ as in (table 2). There was significant relation between CIPNM and age ( $\mathrm{p}=0.04)$ (table 3), also the duration of hospitalization and the duration of mechanical ventilation had significant relation to CIPNM ( $\mathrm{p}=0.002,0.0014$ respectively) (table 4$)$. The incidence of pediatric ICUAW was high especially with the group pathological factors associated with the disease $32.3 \%$ and sepsis $38.7 \%$ (table 5). CIPNM had high significant relation to fasting blood sugar (FBS) and significant relation with C reactive protein (CRP), erythrocyte sedimentation rate (ESR) and creatine phosphokinase (CPK) (table 6). 
Table 1:- shows descriptive analysis and Laboratory parameters of the studied subjects

\begin{tabular}{|c|c|}
\hline Descriptive analysis & $\mathbf{n}=\mathbf{5 0}$ \\
\hline $\begin{array}{c}\text { Age (months) } \\
\text { Mean } \pm \text { SD } \\
\text { Range }\end{array}$ & $\begin{array}{c}55.3 \pm 39.8 \\
18-144\end{array}$ \\
\hline $\begin{array}{cl}\text { Gender } & \\
& \text { Male } \\
& \text { Female }\end{array}$ & $\begin{array}{l}21(42 \%) \\
29(58 \%)\end{array}$ \\
\hline $\begin{array}{c}\text { Causes of admission } \\
\text { Sepsis } \\
\text { Pneumonia } \\
\text { Cardiac } \\
\text { Combined causes }\end{array}$ & $\begin{array}{c}19(38 \%) \\
16(32 \%) \\
4(8 \%) \\
11(22 \%)\end{array}$ \\
\hline $\begin{array}{c}\text { Duration of ventilation } \\
\text { Mean } \pm \text { SD } \\
\text { Range }\end{array}$ & $\begin{array}{c}8.3 \pm 4.2 \\
3-17\end{array}$ \\
\hline Laboratory parameters & \\
\hline $\begin{array}{l}\text { CRP } \\
\text { Mean } \pm \text { SD } \\
\quad \text { Range }\end{array}$ & $\begin{array}{c}25.8 \pm 21.3 \\
4-65\end{array}$ \\
\hline $\begin{array}{l}\text { ESR } \\
\text { Mean } \pm \text { SD } \\
\quad \text { Range }\end{array}$ & $\begin{array}{c}23.1 \pm 7.7 \\
9-40\end{array}$ \\
\hline $\begin{array}{l}\text { CPK } \\
\text { Mean } \pm \text { SD } \\
\quad \text { Range }\end{array}$ & $\begin{array}{c}236.1 \pm 91 \\
120-360 \\
\end{array}$ \\
\hline $\begin{array}{l}\text { FBS } \\
\text { Mean } \pm \text { SD } \\
\quad \text { Range }\end{array}$ & $\begin{array}{c}158.3 \pm 57.1 \\
75-315\end{array}$ \\
\hline $\begin{array}{l}\text { Hb\% } \\
\text { Mean } \pm \text { SD } \\
\quad \text { Range }\end{array}$ & $\begin{array}{c}10.97 \pm 1.6 \\
8-14\end{array}$ \\
\hline $\begin{array}{l}\text { WBCs } \\
\text { Mean } \pm \text { SD } \\
\quad \text { Range }\end{array}$ & $\begin{array}{c}11.85 \pm 4 \\
6-20\end{array}$ \\
\hline
\end{tabular}

FBS $=$ Fasting Blood Sugar, CPK $=$ Creatine Phosphokinase

Table 2:- Incidence of weakness/myopathy or neuropathy and CIPNM among our patients

\begin{tabular}{|l|c|c|}
\hline Items & No & \% \\
\hline Weakness & 31 & 62 \\
\hline Myopathy & 31 & 62 \\
\hline Neuropathy & 27 & 54 \\
\hline CIPNM & & \\
Myopathy and neuropathy & 27 & 54 \\
Normal & 19 & 38 \\
Myopathy only & 4 & 8 \\
\hline
\end{tabular}




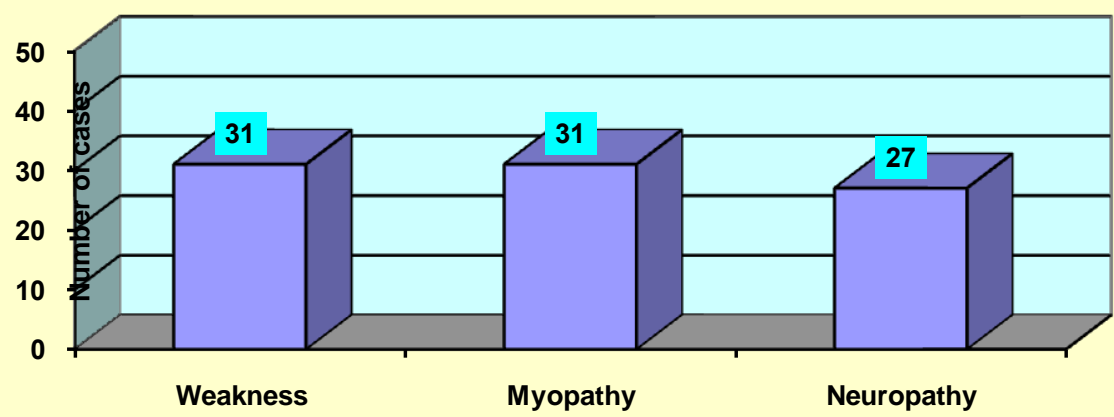

Figure 2:- Incidence of weakness, myopathy and neuropathy

Table 3:- Relation between age and CIPNM and Gender as a risk factor for occurrence of CIPNM

\begin{tabular}{|c|c|c|c|c|c|c|}
\hline \multirow[t]{2}{*}{ Age in month } & \multicolumn{2}{|c|}{$\operatorname{Normal}(n=19)$} & \multicolumn{2}{|c|}{$\operatorname{CIPNM}(\mathrm{n}=31)$} & \multirow[t]{2}{*}{$\mathbf{X}^{2}$} & \multirow[t]{2}{*}{$\mathbf{p}$} \\
\hline & No & $\%$ & No & $\%$ & & \\
\hline$\leq 60$ & 8 & 42.1 & 22 & 71 & \multirow[t]{2}{*}{4.09} & \multirow{2}{*}{$\begin{array}{l}0.04 \\
(\mathrm{~S})\end{array}$} \\
\hline$>60$ & 11 & 57.9 & 9 & 29 & & \\
\hline \multicolumn{7}{|l|}{ Gender } \\
\hline Male & 7 & 36.8 & 14 & 45.2 & \multirow[t]{2}{*}{0.33} & \multirow{2}{*}{$\begin{array}{l}0.56 \\
(\mathrm{NS})\end{array}$} \\
\hline Female & 12 & 63.2 & 17 & 54.8 & & \\
\hline
\end{tabular}

Table 4:- Relation between duration of hospitalization, duration of mechanical ventilation and CIPNM

\begin{tabular}{|c|c|c|c|c|}
\hline Days of hospitalization & $\operatorname{Normal}(\mathrm{n}=19)$ & CIPNM(n = 31) & $\mathbf{t}$ & $\mathbf{p}$ \\
\hline Mean \pm SD & $13.5 \pm 5$ & $18.5 \pm 5.35$ & \multirow[t]{2}{*}{3.25} & \multirow{2}{*}{$\begin{array}{l}0.002 \\
(\mathrm{~S})\end{array}$} \\
\hline Range & $4-23$ & $10-30$ & & \\
\hline \multicolumn{5}{|l|}{ Days on ventilation } \\
\hline Mean \pm SD & $6.05 \pm 3.1$ & $9.8 \pm 4.19$ & \multirow[t]{2}{*}{3.36} & \multirow{2}{*}{$\begin{array}{l}0.0014 \\
\text { (S) }\end{array}$} \\
\hline Range & $3-13$ & $3-17$ & & \\
\hline
\end{tabular}

Table 5:- Relation between cause of admission and occurrence of CIPNM

\begin{tabular}{|l|l|l|l|l|l|l|}
\hline \multirow{2}{*}{ Diagnosis } & \multicolumn{2}{|l|}{ Normal(n= 19) } & \multicolumn{2}{l|}{ CIPNM(n= 31) } & \multirow{2}{*}{$\mathbf{X}^{\mathbf{2}}$} & \multirow{2}{*}{ P } \\
\cline { 2 - 7 } & No & $\mathbf{\%}$ & No & $\mathbf{\%}$ & 0.02 & $0.89(\mathrm{NS})$ \\
\hline Sepsis & 7 & 36.8 & 12 & 38.7 & 1.44 & $0.23(\mathrm{NS})$ \\
\hline Pneumonia & 8 & 42.1 & 8 & 25.8 & 1.58 & $0.2(\mathrm{NS})$ \\
\hline Cardiac & 3 & 15.8 & 1 & 3.2 & 5 & $0.025(\mathrm{~S})$ \\
\hline Multiple causes & 1 & 5.3 & 10 & 32.3 & 5 & \\
\hline
\end{tabular}

Table 6:- Some laboratory findings in relation to CIPNM

\begin{tabular}{|l|l|l|l|l|}
\hline Laboratory findings & $\begin{array}{l}\text { Normal } \\
(\mathbf{n = 1 9 )}\end{array}$ & $\begin{array}{l}\text { CIPNM } \\
(\mathbf{n = 3 1})\end{array}$ & $\mathbf{t}$ & $\mathbf{p}$ \\
\hline $\begin{array}{l}\text { CRP } \\
\text { Mean } \pm \text { SD } \\
\text { Range }\end{array}$ & $\begin{array}{c}14.7 \pm 13.5 \\
4-47\end{array}$ & $\begin{array}{c}32.5 \pm 22.5 \\
4-65\end{array}$ & 7.07 & $\begin{array}{l}0.007 \\
(\mathrm{~S})\end{array}$ \\
\hline $\begin{array}{l}\text { ESR } \\
\text { Mean } \pm \text { SD } \\
\text { Range }\end{array}$ & $\begin{array}{c}19 \pm 5.2 \\
9-32\end{array}$ & $\begin{array}{c}25.7 \pm 7.9 \\
13-40\end{array}$ & 3.25 & $\begin{array}{l}0.002 \\
(\mathrm{~S})\end{array}$ \\
\hline $\begin{array}{l}\text { CPK } \\
\begin{array}{l}\text { Mean } \pm \text { SD } \\
\text { Range }\end{array}\end{array}$ & $\begin{array}{c}138.3 \pm 14.1 \\
120-185\end{array}$ & $\begin{array}{c}246.6 \pm 62.7 \\
140-300\end{array}$ & 7.06 & $\begin{array}{l}<0.001 \\
(\mathrm{~S})\end{array}$ \\
\hline $\begin{array}{l}\text { FBS } \\
\text { Mean } \pm \text { SD } \\
\text { Range }\end{array}$ & $\begin{array}{c}103.9 \pm 19.7 \\
75-160\end{array}$ & $\begin{array}{c}191.6 \pm 45.6 \\
83-315\end{array}$ & 7.9 & $\begin{array}{l}<0.001 \\
(\mathrm{HS})\end{array}$ \\
\hline
\end{tabular}

$\mathrm{CRP}=\mathrm{C}$ reactive protein, $\mathrm{ESR}=$ erythrocyte sedimentation rate, $\mathrm{CPK}=$ creatine phosphokinase, $\mathrm{FBS}=$ fasting blood sugar 


\section{Discussion:-}

Our focus on the PICU patients who regained normal or almost normal consciousness has several advantages: Awakening is a clinically important event during ICU stay, because this is usually the starting point of the process that will lead to weaning from the ventilator and to progressive recovery, Identification of a peripheral neuromuscular abnormality that might interfere with this recovery process is the cornerstone in pediatric patient who regain consciousness after septic, ischemic, or drug-related encephalopathy, and Return to normal or almost normal consciousness and comprehension allows all pediatric patients to undergo clinical assessment using simple bedside tests, such as limb muscle strength evaluation.

The systematic clinical detection of paresis in our study showed that a $62 \%$ of PICU patients who had undergone mechanical ventilation for 7 or more days and achieved satisfactory recovery of consciousness had severe motor weakness. This syndrome was characterized by a symmetrical alteration in muscle strength mainly in the proximal regions of the limbs. We found a sensory-motor axonopathy in all of the PICU-acquired weakness patients. Although Bolton et al. considered peripheral neuropathy to be the main mechanism of ICUAW; our findings suggest that both peripheral nerve and muscle are at the origin of ICU-AW and that the term critical illness polyneuropathy may be too restrictive [12].

Hund et. al, found that the incidence of CIPNM in 98 prospectively studied critically ill patients was 33\%; This incidence was high in our study 54\%; While in previous studies using similar inclusion criteria, this varied from 33 to $44 \%$ [13]. When patients suffered from sepsis; the incidence increases up to $70 \%$ [14]

In our study, the duration of hospitalization and duration of ventilation were significantly higher in PICU-acquired weakness patients than in the controls, suggesting that the duration plays a significant role in ICU-AW. That was parallel to Du Bois and Almon, who hypothesized that the duration of mechanical ventilation before awakening was also significantly associated with the occurrence of ICU-AW and likely reflects the negative effect of immobilization on neuromuscular function [15]

Diaz et al. observed septic patients in an ICU searching for incidence of ICU-AW and risk factors prevalence and to compare duration of mechanical ventilation between ICU-AW and control patients. They showed a great incidence of septic patients (41.7\% of ICU-AW). They have found an association between sepsis and malnutrition. Although steroids could be a risk factor, the muscle biopsy shows a different pattern. No patients were treated with NMBA and all were submitted to strict glycemic control. ICU-AW patients had difficulties in weaning from the artificial respirator, increasing days of mechanical ventilation [16].

In our study although weakness presents more in patients with sepsis; sepsis showed no significant relation with CIPNM, while multiple-organ dysfunction had a significant relation with it.

Weber-Carstens et al. investigated predisposing risk factors for the development of non-excitable muscle membrane during early critical illness, They concluded that systemic inflammation during early critical illness turned out to be the main risk factor for the development of non-excitable muscle membrane indicating CIM. It may be hypothesized that inflammation-induced impairment of growth factor-mediated intracellular signaling is involved in the pathophysiology of CIM [17].

Creatine phosphokinase (CPK) values were mildly elevated in our PICUAW patients $<400$ and Amir S. and Réza Behrouz, hypothesized that CPK may be normal in people who have CIM but do not have muscle necrosis or have scattered muscle necrosis. Furthermore, in those with CIM and muscle necrosis, the CK elevation is typically transient and may be missed on a single laboratory analysis [18]

FBS had highly significant relations with CIPNM patients in our study. Christie M and Eddy Fan concluded; hyperglycemia may be an important risk factor for the development of ICUAW [1], [18].

Brahmbhatt et al. assessed efficacy of combining daily interruption of sedation with physical and occupational therapy on functional outcomes in patients receiving mechanical ventilation in intensive care. They demonstrated that A strategy for whole-body rehabilitation consisting of interruption of sedation and physical and occupational therapy in the earliest days of critical illness was safe and well tolerated, and resulted in better functional outcomes at hospital discharge, a shorter duration of delirium, and more ventilator-free days compared with standard care [19]. 


\section{Conclusion and recommendations:-}

It becomes clear from the research that the incidence of PICUAW was high especially when pathological factors associated with the disease.

So, considering PICUAW is a serious problem, which should be taken into consideration; neurophysiologic testing is recommended for early diagnosis of weakness. Control of causal factors such as the level of blood sugar and minimizing the length of the period of mechanical ventilation is recommended.

\section{References:-}

1. Christie M Lee and Eddy Fan (2012) : ICU-acquired weakness: what is preventing its rehabilitation in critically ill patients?, (C) Lee and Fan; licensee BioMed Central Ltd. http://www.biomedcentral.com/1741-7015

2. Vinay Kukreti, Mosharraf Shamim, and Praveen Khilnani (2014) : Intensive care unit acquired weakness in children: Critical illness polyneuropathy and myopathy. Indian J Crit Care Med. February; 18(2): 95-101

3. Maramattom B V and Wijdicks EF (2006)." Acute neuromuscular weakness in the intensive care unit" .Crit. Care Med. 34(11): 2835-41.

4. De Jonghe B, Sharshar T, Lefaucheur JP, et al. (2002): Paresis acquired in the intensive care unit: a prospective multicenter study. JAMA; 288: 2859-2867.

5. Bolton CF (2005): Neuromuscular manifestations of critical illness. Muscle Nerve; 32:140-163.

6. Lacomis D, Petrella JT, Giuliani MJ (2008): Causes of neuromuscular weakness in the intensive care unit: a study of ninety-two patients. Muscle Nerve; 21:610-617.

7. Wolfgang ZINK, Rainer Kollmar, Stefan Schwab (2009): Critical illness polyneuropathy and myopathy in the intensive care unit in Nature Reviews Neurology 5, 372-379.

8. Hermans, G., De Jonghe, B., Bruyninckx, F. \& van den Berghe, G. Clinical review (2008) : critical illness polyneuropathy and myopathy. Crit. Care 12, 238.

9. Stephen Williams, Iain A. Horrocks, Robert A. Ouvrier, Jonathan Gillis, and Monique M. Ryan (2007): Critical illness polyneuropathy and myopathy in pediatric intensive care: A review. Pediatr Crit Care Med 2007 Vol. 8, No. 1

10. Pandit L, Agrawal A (2006): Neuromuscular disorders in critical illness. Clin Neurol Neurosurg; 108:621-627.

11. Preston DC, Shapiro BE (2013).: Detailed nerve conduction studies; Electromyography and neuromuscular disorders. Clinical-electrophysiologic correlations. USA: Elsevier; 2013 [p. 115-160].

12. Bolton C, Gilbert J, Fhahn A, et al. (2004): Polyneuropathy in critically ill patients. J Neurol Neurosurg Psychiatry; 47:1223-1231.

13. Hund E, Genzwi.irker H, Bohrer H et al. (2007): Predominant involvement of motor fibers in patients with critical illness polyneuropathy. Br J Anaesth; 78:274-278.

14. Hund E (2011): Neurological complications of sepsis: critical illness polyneuropathy and myopathy. Journal of Neurology; 248: 929-934.

15. Du Bois DC, Almon RR (2010): Disuse atrophy of skeletal muscle is associated with an increase in number of glucocorticoid receptors. Endocrinology; 107: 1649-1651.

16. Diaz N, Fuentetaja L, Quecedo L, et al. (2006): ICU-acquired paresis in severe sepsis in an intensive care unit. European Journal of Anaesthesiology; 23: 188-189.

17. Weber-Carstens S, Deja M, Koch S, et al. (2010): Risk factors in critical illness myopathy during the early course of critical illness: A prospective observational study. Critical Care; 14: R119.

18. Amir S. Khoiny, M.D. and Réza Behrouz, D.O( 2011) : Critical Illness Polyneuropathy and Critical Illness Myopathy, Practical Neurology May/June 2011; p 52-56

19. Brahmbhatt N, Murugan R and Milbrandt EB (2010): Early mobilization improves functional outcomes in critically ill patients. Critical Care; 14: 321 